\title{
Comparison between Efficacy of Single Dose Caudal Ropivacaine and Levobupivacaine for Post-Operative Analgesia following Infraumbilical Surgeries in Paediatric Patients
}

\author{
Arun Kumar¹, Manish Kumar Nag², Laxmidhar Dash³, Bisimita Mallick4, Deba Prasad Mohanty 5
}

\begin{abstract}
${ }^{1}$ Assistant Professor, Department of Anaesthesiology, MKCG MCH, Berhampur, Odisha, India. ${ }^{2}$ Junior Resident, Department of Anaesthesiology, MKCG MCH, Berhampur, Odisha, India. ${ }^{3}$ Professor, Department of Anaesthesiology, MKCG MCH, Berhampur, Odisha, India. ${ }^{4}$ Assistant Professor, Department of Obstetrics and Gynaecology, BB MCH, Bolangir, Odisha, India. ${ }^{5}$ Professor and HOD, Department of Anaesthesiology, MKCG MCH, Berhampur, Odisha, India.
\end{abstract}

\section{ABSTRACT}

\section{BACKGROUND}

Caudal epidural is the most commonly used technique for post-operative pain management in paediatric age group, is virtually free of measurable hemodynamic effect, thus adding a new dimension to the evolving necessity of paediatric postoperative pain management. Though levobupivacaine, ropivacaine, bupivacaine are the safer drugs and the addition of fentanyl increases the effective duration of analgesia. Our present study was designed to compare the efficacy of single dose caudal ropivacaine and levobupivacaine for postoperative analgesia following infraumbilical surgeries in paediatric patient.

\section{METHODS}

Sixty children in total, aged between $1 \mathrm{yr}$. and 10 yrs. of ASA 1 \& 2, posted for infraumbilical surgeries were included in the study. Written consent was obtained from parents of the children. Children were divided into 2 equal groups for the study. Group (R) received Ropivacaine 0.25\%, $1 \mathrm{ml} / \mathrm{kg}$ and Group (L) received Levobupivacaine $0.25 \% 1 \mathrm{ml} / \mathrm{kg}$. Assessment of pain was done using CHIPPS score and duration of motor blockade in term of modified Bromage scale was also noted and basic parameters like SBP, MAP, $\mathrm{HR}, \mathrm{SPO}_{2}$, were monitored intra-operatively.

\section{RESULTS}

The two groups were comparable in term of demographic characteristics. Haemodynamic status in patients in both groups was equally stable intra operatively, Duration of post-operative analgesia was almost similar in both the groups ( $\mathrm{R}=306+-15.509 \mathrm{MIN}, \mathrm{L}=305+-18.633 \mathrm{MIN}, \mathrm{P}=.553)$. In both the groups no residual motor loss persisted postoperatively. Requirement of total dose of rescue analgesic was also similar in both groups. No group showed any significant side effects.

\section{CONCLUSIONS}

In children caudal administration of Ropivacaine and Levobupivacaine provides comparable postoperative analgesia., without motor paralysis, allows early ambulation and discharge following short infra umbilical surgeries in paediatric age.

\section{KEY WORDS}

Caudal Anaesthesia, Ropivacaine, Levobupivacaine

\author{
Corresponding Author: \\ Dr. Arun Kumar, \\ Assistant Professor, \\ Department of Anaesthesiology, \\ QR No. 4R/9, \\ MKCG Medial College Campus, \\ Berhampur-4, Odisha, India. \\ E-mail:fun276@gmail.com
}

DOI: $10.14260 / j e m d s / 2019 / 617$

Financial or Other Competing Interests: None.

How to Cite This Article:

Kumar A, Nag MK, Dash $L$, et al. Comparison between efficacy of single dose caudal ropivacaine and levobupivacaine for post-operative analgesia following infraumbilical surgeries in paediatric patients. J. Evolution Med. Dent. Sci. 2019;8(37):2841-2845, $10.14260 /$ jemds/2019/617

Submission 22-07-2019,

Peer Review 01-09-2019,

Acceptance 07-09-2019,

Published 16-09-2019. 


\section{BACKGROUND}

The management of intraoperative and post-operative pain in paediatric patients can be accomplished by using multimodal approach. Various pharmacological methods to treat pain include Paracetamol, Nonsteroidal anti-inflammatory drugs (NSAIDS), Opioids, and Neuraxial or Regional local anaesthetics. Neuraxial blocks are particularly well tolerated in paediatric population and regional analgesia is now the preferred technique for postoperative pain management in this group. Caudal epidural is commonly used regional technique for infraumbilical surgery in children which provides pain relief both in intraoperative and postoperative period. Caudal block is one of the simplest and safest techniques in paediatric surgery with high success rate 1. Lower pain score has been observed with caudal block when combined with general anaesthesia than with general anaesthesia alone. Caudal block combined with general anaesthesia can reduce the amount of inhaled and intravenous anaesthetic agents, attenuate the stress response of surgery, facilitates rapid and smooth recovery with minimal postoperative vomiting providing good postoperative analgesia ${ }^{2}$. Caudal block results in sensory analgesia, motor block and sympathetic block depending on the concentration, dose and volume of local anaesthetics. Complications are rare, about 1 case per 1000 procedures, and usually minor ${ }^{3}$. Single dose caudal block with local anaesthetics has been used safely and effectively in paediatric surgical procedures for provision of post-operative analgesia. Caudal epidural technique is well tolerated in paediatric population when combined with GA to suppress pain response in post-operative period.

Several local anaesthetic agents are in use to produce neuraxial block. Levobupivacaine is the pure S (-) enantiomer of Bupivacaine. Pharmacological studies demonstrated less affinity for and less degree of depressant effects on myocardium and vital centres in the brain having a superior pharmacokinetic profile. Clinically, levobupivacaine is well tolerated in a variety of regional anaesthesia technique after bolus administration.

Ropivacaine which is prepared from $\mathrm{S}(-)$ enantiomer also reported to have better safety profile than Bupivacaine, with less cardiotoxicity and less risk to CNS. Pharmacological studies have demonstrated the safety of caudal ropivacaine in children which have shown to be as effective as bupivacaine. $4,5,6,7$ Both the drugs have shown less extensive and shorter duration of motor block compared to racemic bupivacaine. 5,8

This present study was carried out to observe which one of the two local anaesthetic agents give prolonged analgesia with less residual motor block with same amount of drug of same concentration in paediatric patients undergoing infraumbilical surgeries.

\section{METHODS}

The present study was conducted at M.K.C.G. Medical Collage and Hospital after obtaining clearance from institutional ethical committee \& scientific committee. This randomized double blind study is having 60 children of either sex, aged between 1 year to 10 years of American Society of Anaesthesiologists physical Status (ASA) I and II, posted for infraumbilical surgeries the procedures include inguinal hernia repair, orchidopexy, hypospadias correction, urethroplasty, any orthopaedic surgeries in lower limbs with an anticipated duration of less than 90 minutes. Written informed consent was taken from the parents of the children. Children were divided into two equal groups for the study. Children having known hypersensitivity to amide local anaesthetics, known active co-morbid conditions like cardiorespiratory, renal, hepatic, neurological, neuromuscular disorder, cutaneous infection at the site of caudal injection, blood clotting disorders \& blood dyscrasias, platelet count $<100000 /$ cumm. and all emergency surgeries were excluded.

By using double blind randomized control design these children were divided into two groups as group $\mathrm{R}$ and $\mathrm{L}$. Group (R) with 30 children received Ropivacaine $0.25 \% 1$ $\mathrm{ml} / \mathrm{kg}$ and Group (L) with 30 children received Levobupivacaine $0.25 \% 1 \mathrm{ml} / \mathrm{kg}$.

Children were administered general anaesthesia and after intubation caudal anaesthesia was administered with either of the study drugs. Patients were received at operation theatre, patients NPO status and Consent was verified and general anaesthesia was induced by $100 \% \mathrm{O}_{2}$ and increasing dial concentration of Sevoflurane up to 4- 6 MAC through the appropriate paediatric mask using Jackson-Rees modification of Ayre's T-piece. All the monitor attachments were made subsequently to record vital parameters. Intravenous access was secured using a 22G or 24G I.V. cannula as appropriate for the child's and baseline hemodynamic parameters were noted. Injection Glycopyrrolate $10 \mu \mathrm{g} / \mathrm{kg}$ and inj. Pentazocine $0.5 \mathrm{mg} / \mathrm{kg}$ was given intravenously and tracheal intubation was done with appropriate size of uncuffed PVC endotracheal tube by increasing dial concentration of Sevoflurane up to 5-8 MAC. Anaesthesia was maintained by using $\mathrm{N}_{2} \mathrm{O}: \mathrm{O}_{2}=3: 2$ and intermittent Sevoflurane of 0.2-3 MAC using IPPV throughJackson Rees modification of Ayre's T-piece. Caudal block was then performed under strict aseptic condition. Patient was turned to left lateral position. After confirming the sacral hiatus, the puncture was performed with a sterile disposable hypodermic needle of size $22 \mathrm{G}$ or $23 \mathrm{G}$. The syringe filled with the calculated dose of study drug was then attached to the hub of the needle and gentle aspiration was performed, if no blood or CSF was aspirated, then only either of the study drugs was injected in small increments with repeated aspiration test random numbers. Group $\mathrm{R}$ received Inj. Ropivacaine $0.25 \% 1 \mathrm{ml} / \mathrm{kg}$ and group $\mathrm{L}$ received Inj. Levobupivacaine $0.25 \% 1 \mathrm{ml} / \mathrm{kg}$. The anaesthesiologist who performed the procedure was unaware of the drug he/she administered. At the end of the procedure the point of puncture was covered with antiseptic dressing. The end point of administering caudal block was noted as 0 min. Patient was turned supine and positioned for surgery. Anaesthesia was maintained using $\mathrm{N}_{2} \mathrm{O}: \mathrm{O}_{2}=3: 2$ ratio and intermittent Sevoflurane of 0.2-3MAC using IPPV through-Jackson Rees modification of Ayre's T-piece. The hemodynamic parameters were continuously monitored during intraoperative period. After completion of the procedure child was reversed from general anaesthesia by discontinuing inhalation agent Sevoflurane, after thorough suctioning of oral cavity and oropharynx was done and the child was extubated when 
protective airway reflexes returned. Patients were observed postoperatively in post anaesthesia care area with monitoring of $\mathrm{HR}$ and $\mathrm{SpO}_{2}$ before sending to ward. In the ward the degree of pain was assessed by CHIPPS scale hourly till score was $>4$ or first requirement of rescue analgesic. The motor blockade was assessed by Bromage Scale till it is 0 . Inj. Fentanyl 1.5-2 $\mu \mathrm{gm} / \mathrm{kg}$ was administered intravenous as rescue analgesic at dose of $0.5 \mu / \mathrm{kg}$ body weight once pain score $>4$. Time of requirement of 1 st rescue analgesic and total dose of analgesic consumption were noted.

\section{Statistical Analysis}

Statistical analysis was done using statistical package for social sciences (SPSS) software version 22. Sample size calculation was done with PS power and sample size calculations version 3.1.2. Haemodynamic variables were compared between two groups by Mann Whitney $U$ test. Unpaired Students' t-test was used to compare normally distributed numerical variables such as age and body weight. Categorical variables were compared with Chi-square test or Fishers' exact test, wherever applicable. A p $<0.05$ was taken to be statistically significant.

\section{RESULTS}

\begin{tabular}{|c|c|c|c|c|c|}
\hline \multicolumn{2}{|c|}{ Parameters } & Group R & Group L & p Value & \begin{tabular}{|l} 
Significance \\
\end{tabular} \\
\hline \multicolumn{2}{|c|}{ Age (months) } & $33.00 \pm 17.147$ & $34.50 \pm 16.387$ & .684 & NS \\
\hline \multirow{2}{*}{ Sex } & $\mathrm{M}$ & 22 & 25 & \multirow{2}{*}{.347} & \multirow{2}{*}{ NS } \\
\hline & $\mathrm{F}$ & 8 & 5 & & \\
\hline \multicolumn{2}{|c|}{ Weight $(\mathrm{kg})$} & $14.73 \pm 3.047$ & $14.43 \pm 2.242$ & .665 & NS \\
\hline \multicolumn{6}{|c|}{ Table 1. Demographic Data } \\
\hline
\end{tabular}

\begin{tabular}{|c|c|c|}
\hline Type of Surgery & Group R & Group L \\
\hline Urethroplasty & 5 & 4 \\
\hline Herniotomy & 11 & 8 \\
\hline Orchidopexy & 7 & 7 \\
\hline Orthopaedic Operations in Lower Limbs & 3 & 3 \\
\hline Circumcision & 2 & 5 \\
\hline Eversion of Sac of Hydrocele & 2 & 3 \\
\hline Table 2. Distribution of Type of Surgery Performed \\
\hline
\end{tabular}

\begin{tabular}{|c|c|c|c|}
\hline CHIPPS Score & Group R & Group L & p Value \\
\hline C60 & $1.5 \pm 0.878$ & $1 \pm 0.798$ & 0.992 \\
\hline C120 & $2 \pm 0.379$ & $2 \pm 0.479$ & 0.992 \\
\hline C180 & $2 \pm 0$ & $2 \pm 0$ & 0.992 \\
\hline C240 & $3 \pm 0$ & $3 \pm 0$ & 0.833 \\
\hline C300 & $4 \pm 0.498$ & $4 \pm 0.479$ & 0.896 \\
\hline \multicolumn{4}{|c|}{} \\
\hline
\end{tabular}

\begin{tabular}{|c|c|c|c|c|}
\hline Parameters & Group R & Group L & p Value & Significance \\
\hline $\begin{array}{c}\text { Time of First Rescue } \\
\text { Analgesia }\end{array}$ & $306 \pm 15.509$ & $305 \pm 18.633$ & .553 & NS \\
\hline Total Dose of Fentanyl & $14.73 \pm 3.307$ & $15.5 \pm 2.596$ & .652 & NS \\
\hline \multicolumn{6}{|c|}{ Table 4. Time of First Rescue Analgesia } \\
\hline
\end{tabular}

\begin{tabular}{|l|c|c|c|c|c|}
\hline & $\begin{array}{c}\text { Nausea \& } \\
\text { Vomiting }\end{array}$ & Bradycardia & Hypotension & $\begin{array}{c}\text { Respiratory } \\
\text { Depression }\end{array}$ & $\begin{array}{c}\text { Urinary } \\
\text { Retention }\end{array}$ \\
\hline Group R & 4 & 0 & 0 & 0 & 2 \\
\hline Group L & 4 & 0 & 0 & 0 & 3 \\
\hline \multicolumn{5}{|c|}{ Table 5. Side Effects Observed } \\
\hline
\end{tabular}

The two groups were comparable with respect to age, sex and weight (Table 1).The types of surgery and the duration of surgeries in both the groups were comparable (Table 2). The postoperative pain (table 3) use of rescue analgesia as fentanyl for the first time and the total dose of fentanyl used as analgesia (table 4) were comparable in both the groups without any significant changes. Only few children had nausea and vomiting, some had retention of urine (table 5).
No other complications seen in either of the groups. Table 3 shows changes in Children \& Infants Postoperative Pain Scale score in postoperative periods in two groups. CHIPPS scores were almost similar in both the groups at different times in postoperative period. The differences in mean scores after 60 minutes following caudal injection up to 300 minutes following caudal injection were not statistically significant (Students independent t-test, $\mathrm{P}>0.05$ )

\section{DISCUSSION}

Pain is one of the most unpleasant sensations experienced by human beings. As children have well developed pain pathways \& are more vulnerable to adverse physiological effect of pain, postoperative pain relief in paediatric patients is as important as in adults. Various medications \& techniques are used to control postoperative pain. The advent of regional anaesthesia has added a new dimension to the postoperative pain management even in paediatric populations. Caudal epidural is one of the regional techniques that have been widely accepted over the last few years in the field of paediatric anaesthesia. ${ }^{4}$ The wide acceptance of this procedure is due to easier administration of the technique and extent of safety and tolerance ${ }^{5}$ The sympathetic immaturity, diminished autonomic adaptability of the heart and smaller vascular bed in the lower extremities provide excellent hemodynamic stability during neuraxial block in paediatric patients. Usually preloading with fluid and use of vasoactive agent are not required. So caudal epidural block is commonly used to supplement general anaesthesia with reduced requirement of anaesthetic agents along with good postoperative pain relief.

Similarly, the discovery of newer generation of highly efficacious and relatively safe group of local anaesthetic agents has begun a new era in the domain of postoperative analgesia. Though bupivacaine is the most widely used local anaesthetic since its discovery, it is associated with cardiac and central nervous system toxicity. Newer

Drugs like ropivacaine and levobupivacaine are gaining popularity due to lesser cardiotoxicity, lesser motor blockade \& similar degree of analgesia with equipotent dose of bupivacaine.5,6,7 Previous studies published compared caudal bupivacaine with either levobupivacaine or ropivacaine.5,6,7 Till date only few studies have been published comparing analgesic efficacy of two new drugs levobupivacaine with ropivacaine

The present study was designed to determine \& compare the duration of analgesia with single dose caudal 0.25 ropivacaine at $1 \mathrm{ml} / \mathrm{kg}$ body weight to same dose of $0.25 \%$ levobupivacaine in infraumbilical surgeries in children. Caudal block administered after induction of general anaesthesia with Sevoflurane with endotracheal intubation without muscle relaxant. Anaesthesia was maintained with $\mathrm{O}_{2}, \mathrm{NO}_{2}$ and sevoflurane. Postoperative pain was assessed by CHIPPS scale and duration of analgesia was obtained by noting the time of first rescue analgesia. Perioperative haemodynamic changes, residual motor block and any obvious side effects like nausea-vomiting, respiratory depression, retention of urine were also taken into consideration. 
Clinically the demographic parameters were almost similar with no statistically significant difference between the groups in terms of age, sex, and body weight Hence the groups were comparable with respect to demographic characteristics \& the effect of these parameters on drug effect were equal in both groups. Difference in duration of surgery between the two groups were not statistically significant. It is evident that the intraoperative hemodynamic profile, which is an indirect indicator of intra and postoperative pain, is well maintained with ropivacaine as compared to levobupivacaine.

Children and Infants Postoperative Pain Scale score in postoperative periods in two groups. CHIPPS score were almost similar in both the groups at different times in postoperative periods. The differences in mean score after 60 minutes following caudal injection up to 300 minutes following caudal injection were not statistically significant.

The use of first rescue analgesia after caudal block as inj. fentanyl in both the groups is also not significant. We also noted that only few children had nausea and vomiting, and some had retention of urine in both the groups.

Ingelmo P et al in $2009{ }^{(9)}$ performed a study to determine the minimum local analgesic concentrations of a caudal single shot of ropivacaine and levobupivacaine in children and to describe the upper dose response curve. CHIPPS scores assessed at $10 \mathrm{~min}$ intervals up to $60 \mathrm{~min}$ after awakening were not significantly different between drugs (KruskalWallis rank test $\mathrm{P}=0.34,0.78,0.57,0.45,0.67,0.57$ respectively).

M. Astuto et al. ${ }^{10}$ compared the onset, intra operative tolerance, post-operative analgesic effect, motor blockade \& any adverse reaction produced by single dose of Levobupivacaine with Ropivacaine by caudal route. During the first 4 hour after placement of caudal block, the pain assessment score according to the Children Hospital Eastern Ontario Pain Scale (CHEOPS) was comparable for the two groups.

Christian Breschanet. $\mathrm{Al}^{11}$ compared postoperative analgesic efficacy, analgesic duration and motor blockade of levobupivacaine, ropivacaine and bupivacaine administered caudally in equal concentrations to children undergoing elective minor surgery in a study. Postoperative pain scoring evaluated with Children's and Infant's Postoperative Pain Scale (CHIPPS) scale showed no statistical difference between groups.

Biswas S, et al.(12) in 2013 compared post-operative analgesic efficacy of a single dose administration of caudal Levobupivacaine $(0.25 \%)$ vs Ropivacaine $(0.25 \%)$ in children undergoing elective infra umbilical surgeries with anticipated duration of surgery of less than 90 minutes and they found both the drugs having same efficacy. B. Locatelli et al ${ }^{13}$ compared post-operative analgesic efficacy of $0.25 \%$ Levobupivacaine, $0.25 \%$ Ropivacaine \& $0.25 \%$ Bupivacaine by caudal route and post-operative pain was evaluated using the Children and Infants Postoperative Pain Scale (CHIPPS) which was comparable. G. Ivani et al. ${ }^{14}$ investigated the issue comparing equal concentrations $(0.2 \%)$ of ropivacaine and $0.2 \%$ of levobupivacaine in children undergoing minor subumbilical surgery. During the 24 -h observation period CHIPPS scores were almost identical for the two study groups. In our study the time period for first rescue analgesia was approximately equal in both the groups The present study thus corroborates the findings of previous studies, that ropivacaine has equipotent analgesic activity as levobupivacaine, when given caudally. No residual motor block was observed in our study in any of the groups in immediate postoperative period. Thus, present study corroborates the findings of previous studies.

\section{CONCLUSIONS}

In children caudal administration of Ropivacaine and Levobupivacaine provides similar and comparable postoperative analgesia, without motor paralysis, allowing early ambulation \& discharge following short infra-umbilical surgeries. Further studies are needed to establish these facts.

\section{REFERENCES}

[1] Giaufre E, Dalens B, Gombert A. Epidemiology and morbidity of regional anaesthesia in children: a one-year prospective survey of the French-Language Society of Paediatric Anaesthesiologists (ADARPEF). Anesth Analg 1996;83(5):904-12.

[2] Deng XM, Xiao WJ, Tang GZ, et al. The minimum local anaesthetic concentration of ropivacaine for caudal analgesia in children. Anesth Analg 2002;94(6):1465-8.

[3] Dalens B, Hasnaoui A. Caudal anaesthesia in paediatric surgery: success rate and adverse effects in 750 consecutive patients. Anesth Analg 1989;68(2):83-9.

[4] Da Conceicao MJ, Coelho L. Caudal anaesthesia with $0.375 \%$ ropivacaine or $0.375 \%$ bupivacaine in pediatric patients. Br J Aneasth 1998;80(4):507-8.

[5] Ivani G, Lampugnani E, Torre $\mathrm{M}$, et al. Comparison of ropivacaine with bupivacaine for paediatric caudal block. Br J Anaesth 1998;81(2):247-8.

[6] Koing H, Krenn CG, Glaser C, et al. The dose-response of caudal ropivacaine in children. Anaesthesiology 1999;90(5):1339-44.

[7] Luz G, Innerhofer P, Haussler B, et al. comparison of ropivacaine $0.1 \%$ and $0.2 \%$ with bupivacaine $0.2 \%$ for single-shot caudal anaesthesia in children. Paediatr Anaesth 2000;10(5):499-504.

[8] Frawley GP, Downie S, Huang GH. Levobupivacaine caudal anesthesia in children: a randomized doubleblind comparison with bupivacaine. Paediatr Anaesth 2006;16(7):754-60.

[9] Ingelmo P, Frawley G, Astuto M, et al. Relative analgesic potencies of levobupivacaine and ropivacaine for caudal anesthesia in children. Anesth Analg 2009;108(3):80513.

[10] Astuto M, Disma N, Arena C. Levobupivacaine 0.25\% compared with ropivacaine $0.25 \%$ by the caudal route in children. Eur J Anesthesiol 2003;20(10):826-30.

[11] Breschan C, Jost R, Krumpholz R, et al. A prospective study comparing the analgesic efficacy of levobupivacaine, ropivacaine and bupivacaine in pediatric patients undergoing caudal blockade. Pediatric Anesthesia 2005;15(4):301-6. 
[12] Biswas S, Mukherjee G, Sarkar UK, et al. Randomized, double blind controlled trial to compare post-operative analgesic efficacy of a single dose administration of caudal Levo-Bupivacaine $(0.25 \%)$ VS Ropivacaine $(0.25 \%)$ in infra-umbilical surgeries in children. Journal of Evolution of Medical and Dental Sciences 2013;2(31):5740-7.

[13] Locatelli B, Ingelmo P, Sonzogni V, et al. Randomized, double-blind, phase III, controlled trial comparing levobupivacaine $0.25 \%$, ropivacaine $0.25 \%$ and bupivacaine $0.25 \%$ by the caudal route in children. $\mathrm{Br} \mathrm{J}$ Anaesth 2005;94(3):366-71.
[14] Ivani G, De Negri P, Lonnqvist PA, et al. Caudal anesthesia for minor pediatric surgery: a prospective randomized comparison of ropivacaine $0.2 \%$ vslevobupivacaine 0.2\%. Paediatr Anaesth 2005;15(6):491-4. 